\title{
A Teoria da Atividade na Produção de Material Didático Digital Interativo de Matemática
}

\author{
The Activity Theory in Mathematics Interactive \\ Digital Didatic Material
}

\author{
Aparecida Santana de Souza Chiari* \\ ORCID iD 0000-0001-7865-9356 \\ Marcelo de Carvalho Borba** \\ ORDID iD 0000-0003-3101-5486 \\ Daise Lago Pereira Souto*** \\ ORCID iD 0000-0001-6832-6099
}

\begin{abstract}
Resumo
Neste artigo discutimos o modo como a linguagem matemática formal, as tecnologias digitais, a internet, os ambientes virtuais de aprendizagem e a interação entre participantes de cursos a distância podem influenciar e transformar a produção de conhecimento em cursos a distância. Consideramos a pesquisa que deu origem a este artigo como um estudo de caso coletivo, pois os dados foram produzidos durante o desenvolvimento de disciplinas de Álgebra Linear de quatro cursos de Licenciatura em Matemática a distância, vinculados à Universidade Aberta do Brasil. Fundamentamos nossas análises na teoria da atividade e na visão epistemológica que circunda o construto seres-humanos-com-mídias. Metodologicamente, adotamos o paradigma qualitativo, tendo como fontes de produção de dados a observação em ambientes virtuais de aprendizagem, entrevistas, projetos político-pedagógicos e notas de campo. A análise dos dados foi alicerçada na teoria enraizada na própria teoria da atividade. Os resultados indicaram que a dificuldade em comunicar e expressar a linguagem matemática formal no ambiente virtual de aprendizagem gerou tensões e transformações que resultaram na produção de Material Didático Digital Interativo.
\end{abstract}

Palavras-chave: MDDI. Teoria Enraizada. Educação a Distância. Álgebra Linear. Tecnologias Digitais.

\footnotetext{
* Doutora em Educação Matemática pela Universidade Estadual Paulista "Júlio de Mesquita Filho" (UNESP). Docente da Universidade Federal de Mato Grosso do Sul (UFMS), Campo Grande, MS, Brasil. Endereço para correspondencia: Av. Costa e Silva, s/n, Bairro Universitário, Campo Grande, MS, Brasil, CEP: 79070-900. Email: cidach@gmail.com.

** Doutor em Educação Matemática pela Cornell University. Docente da Universidade Estadual Paulista "Júlio de Mesquita Filho" (UNESP), Rio Claro, SP, Brasil. Endereço para correspondencia: Av. 24-A, 1515, Bela Vista, Rio Claro, SP, Brasil, CEP: 13506-900. E-mail: marcelo.c.borba@unesp.br.

**** Doutora em Educação Matemática pela Universidade Estadual Paulista "Júlio de Mesquita Filho" (UNESP). Docente da Universidade do Estado de Mato Grosso (UNEMAT), Barra do Bugres, MT, Brasil. Endereço para correspondencia: Rua A, s/n, Cohab São Raimundo, Barra do Bugres, MT, Brasil, CEP: 78390-000. E-mail: daise@unemat.br.
} 


\begin{abstract}
In this article, we discuss how the formal mathematical language, digital technologies, the internet, virtual learning environments, and the interaction between distance learning participants can influence and transform the production of knowledge in distance learning courses. We consider the research that gave rise to this article as a collective case study, since the data were produced during the development of Linear Algebra disciplines of four distance teacher education courses in Mathematics linked to the Open University of Brazil (UAB). We base our analyzes on the theory of activity and the epistemological view that surrounds the construct humans-withmedia. Methodologically, we adopt the qualitative paradigm, having as sources of data production observation in virtual learning environments, interviews, political pedagogical projects and field notes. Data analysis was based on the grounded theory rooted in the activity theory itself. The results indicated that the difficulty in communicating and expressing the formal mathematical language in the virtual learning environment generated tensions and transformations that resulted in the production of interactive digital didactic material.
\end{abstract}

Keywords: IDDM. Grounded Theory. Distance Education. Linear Algebra. Digital Technologies.

\title{
1 Introdução
}

Dificilmente encontraremos alguém que discorde do lugar de destaque que o livro didático ocupa como fonte de pesquisa para o professor preparar sua aula. Por outro lado, a forma como este recurso é utilizado, segundo Ribeiro e Amaral (2016), depende de vários fatores, como o conteúdo do livro, os objetivos pedagógicos, conhecimentos prévios do professor, entre outros. Poderíamos adicionar que esta forma pode ser específica também à modalidade de ensino. Em nosso caso, investigamos o ensino de Matemática a distância.

Destarte, o livro didático, as experiências prévias do professor e a linguagem oral e/ou escrita que este utiliza em suas aulas, além de relacionarem-se entre si, estão entre fatores que influenciam de modo significativo a maneira como os alunos se expressam. Quando particularizamos essa afirmação ao contexto da Educação a Distância (EaD), estamos diante de um cenário de investigação qualitativamente diferente do presencial, se considerarmos a linguagem formal matemática, a simbologia própria que nela está presente e as ferramentas utilizadas na $\mathrm{EaD}$ para comunicação entre professores, tutores e alunos.

Em Borba, Chiari e Almeida (2018) são discutidos novos papéis das tecnologias digitais a partir das interações que ocorrem em Ambientes Virtuais de Aprendizagem (AVAs). A partir dessa discussão, foi possível problematizar também novos papéis para alunos e professores nesses espaços. Além dessas mudanças, acreditamos que a própria produção de conhecimento se transforma diante desse contexto. Assim, neste artigo, nosso objetivo é analisar o modo como a linguagem matemática formal, as tecnologias digitais, a internet, os ambientes virtuais de aprendizagem e a interação entre participantes de cursos a distância podem influenciar e transformar a produção de conhecimento. Nosso foco está na relação 
entre esses elementos, buscando problematizar algumas tensões que surgem em contextos constituídos por eles.

\section{Linguagem matemática formal, Tecnologias e Educação Matemática}

Fan (2013) argumenta, sobre a pesquisa que envolve livros didáticos, que esta deve valorizar aspectos correlacionais e causais, pontuando que, para tanto, os pesquisadores devem "ir além da análise de livros didáticos, comparação de livros didáticos e uso de livros didáticos para um novo paradigma de pesquisa que emprega métodos mais empiricamente baseados e particularmente experimentais" (FAN, 2013, p. 776, tradução nossa).

Refletindo sobre as recomendações de Fan (2013), nosso interesse reside na tentativa de ir além da análise e da comparação de livros didáticos e das maneiras de uso. Para nós, a relação entre a linguagem matemática formal - apresentada nos livros didáticos, mas utilizada em espaços para além deles, como nas próprias aulas de Matemática, por professores e alunos - as tecnologias digitais, a internet e a interação que ocorre em ambientes virtuais de aprendizagem será especialmente relevante.

As tecnologias digitais e a internet cercam o ser humano há algum tempo e sua influência em nossa vida cresce a uma velocidade impressionante. Villarreal e Borba (2010) exploram a influência da internet na Educação a Distância e afirmam que ela criou novas possibilidades para esta modalidade de ensino. Em Educação Matemática, por exemplo, ao relacionarmos o advento da internet com elementos como geometria dinâmica, diversificados modos de comunicação e fácil acesso a vídeos em plataformas ou repositórios, entre outros, constituímos novos cenários investigativos para a área (BORBA; SCUCUGLIA; GADANIDIS, 2014).

Dentro dessa perspectiva, nosso interesse foi observar o uso de tecnologias digitais em Ambientes Virtuais de Aprendizagem de alguns cursos a distância de formação de professores de Matemática.

\section{Teoria da Atividade e Seres-humanos-com-mídias}

Para este artigo, nos apoiaremos na vertente da Teoria da Atividade proposta por Engeström (1987, 2001), que reorganiza algumas concepções de Leontiev (1978), faz releituras de conceitos vygostskyanos e apresenta ideias originais para analisar a atividade humana como uma organização sistêmica (Figura 1). 


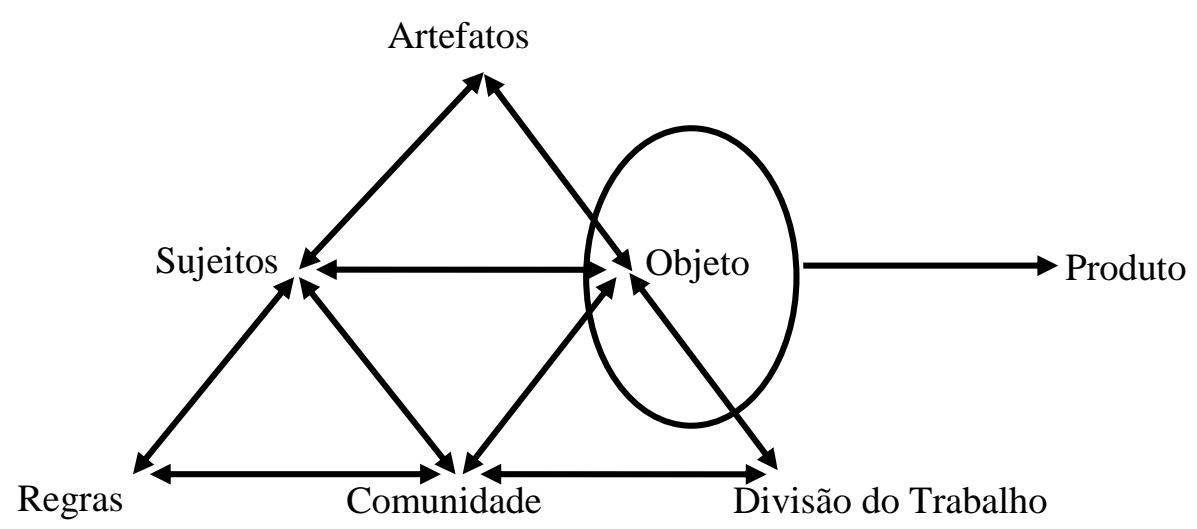

Figura 1 - Representação do sistema de atividade humana Fonte: Baseado em Engeström (1987).

Para Engeström (2001), o diagrama triangular da Figura 1, visto como parte de uma rede de relações com outros sistemas de atividade, representa a unidade mínima de análise e é o primeiro de cinco princípios que ajudam na compreensão da atividade. Souto e Borba (2016, p. 221) afirmam que

[...] Engeström (1987) procura integrar sujeitos (todos que possuem "agency", ou seja, poder de ação), objeto ("matéria-prima" ou "espaço problema" para o qual a atividade é direcionada), artefatos (instrumentos e signos), regras (normas que regulam as relações no sistema), comunidade (todos que de algum modo medeiam a relação entre os sujeitos e o objeto da atividade) e divisão do trabalho (negociação de responsabilidades que é realizada com base nas regras). Ele considera que esses elementos juntos formam um todo unificado. Com essa estrutura, nomeada por ele de sistema de atividade, o autor coloca em destaque a natureza coletiva da atividade e, ao mesmo tempo, estende o conceito de mediação de Vygotsky para o contexto cultural.

O "todo unificado" a que Engeström (1987) se refere está diretamente ligado às relações dialéticas que ocorrem entre os elementos do sistema. Desse modo, apesar de o diagrama que faz referência a um sistema de atividade (Figura 1) ser triangular, o que do ponto de vista matemático poderia remeter à ideia de uma estrutura rígida, Engeström (2001) explica que, em sistemas de atividade, há processos de contínuos movimentos de mudança, decorrentes de crises e rupturas (quarto princípio - contradições internas), que interrelacionados numa formação criativa, composta de elementos, vozes e concepções múltiplas (segundo princípio - multivocalidade), provocam transformações e inovação (quinto princípio - transformações expansivas) que são entendidas do ponto de vista histórico (terceiro princípio - historicidade).

Para analisarmos o modo como a linguagem matemática formal, as tecnologias digitais, a internet, os ambientes virtuais de aprendizagem e as interações que nele ocorrem podem influenciar e transformar a produção de conhecimento em cursos a distância, 
utilizaremos também a visão epistemológica que permeia o construto seres-humanos-commídias.

De acordo com Souto e Borba (2016), esse construto possui duas raízes teóricas. Uma delas está na própria Teoria da Atividade, particularmente nas discussões propostas por Tikhomirov (1981) sobre a reorganização do pensamento. A outra está nas discussões de Lévy (1993) sobre a constituição de novos estilos cognitivos em decorrência do avanço das tecnologias informáticas.

Borba e Villarreal (2005) expandem essas ideias e propõem uma unidade básica de conhecimento que se forma a partir de um pensamento coletivo de seres humanos com tecnologias. Em outras palavras, os seres humanos, ao interagirem com tecnologias, reorganizam o pensamento de acordo com as possibilidades ou restrições que elas oferecem. Assim, a presença delas influencia o tipo de conhecimento que é produzido.

Os autores usam a metáfora "seres-humanos-com-mídias" para enfatizar a produção coletiva de conhecimento, mas também o papel das mídias nessa produção, que muitas vezes é subestimado. Para Borba e Villarreal (2005), o termo "mídias", na metáfora, não está restrito às mídias digitais. Ancorando-se em Lévy (1993), eles interpretam o termo incluindo, também, as mídias oral e escrita. Dessa forma, surge a proposta de que a produção de conhecimento acontece como resultado da interação entre humanos e mídias digitais, mas também entre humanos e escrita, oralidade e outros.

Borba e Villarreal (2005) argumentam que as mídias condicionam o pensamento humano, sem, no entanto, o determinar. Elas moldam os modos de pensamento humano, assim como são moldadas por ele, em um processo dialético denominado por eles de moldagem recíproca.

\section{Aspectos metodológicos}

Em vista do objetivo apresentado anteriormente, consideramos que, metodologicamente, a pesquisa que deu origem a este artigo insere-se dentro do paradigma qualitativo. Utilizamos como fontes de produção de dados: observação, entrevistas, análise de documentos, notas de campo.

A observação ocorreu nos ambientes virtuais de aprendizagem de cada curso/disciplina, ao longo do período de realização das disciplinas em cada universidade. Como acordado com as coordenações de curso ao pedirmos autorização para termos acesso ao ambiente, durante a realização das disciplinas, não houve intervenção de nossa parte no 
andamento das mesmas, embora os professores das disciplinas tivessem ciência de nossa presença virtual no ambiente. Uma das autoras do texto desenvolveu as atividades de observação, mas os registros com potencial de análise foram considerados por todos para análise e produção deste artigo.

Autores como Jaccoud e Mayer (2008, p. 254) afirmam que "de modo geral, a observação de fenômenos, qualquer que seja a sua natureza, constitui o núcleo de todo procedimento científico". Esses autores destacam que a observação é uma técnica direta e não dirigida. Isso porque há contato com os participantes da pesquisa e a observação da realidade é o foco. Eles ressaltam, ainda, que a observação deve apresentar-se ao lado de outras técnicas.

Assim, optamos por utilizar também as entrevistas e a análise documental. Sobre as entrevistas, Bogdan e Biklen (1994) afirmam que, com elas, é possível produzir dados descritivos na linguagem dos próprios participantes da pesquisa. Elas foram realizadas, a princípio, com coordenadores dos cursos e com professores das disciplinas. Durante a análise de dados, quando sentíamos a necessidade de esclarecer alguma ocorrência, ou preencher alguma lacuna identificada, entrávamos em contato com alguns alunos e professores para entrevistá-los com o objetivo de contemplá-las, procedimento previsto na Teoria Enraizada e denominado "amostragem teórica" (STRAUSS; CORBIN, 2008).

Algumas entrevistas foram presenciais, a partir de viagens feitas por uma das autoras deste texto, com este fim específico, e outras foram conduzidas virtualmente. Embora desenvolvidas de modo individual, os roteiros eram sempre discutidos previamente com membros de nosso grupo de pesquisa. Segundo Poupart (2008, p. 227), a entrevista "sempre foi considerada como um meio adequado para levar uma pessoa a dizer o que pensa, a descrever o que viveu ou o que viu, ou aquilo de que foi testemunha”.

Por outro lado, a análise documental dos projetos político-pedagógicos nos deu outra perspectiva dos dados, já que eles nos permitiram olhar para dimensões temporais sem qualquer possibilidade de influência nossa. Como nossa intenção era desenvolver uma análise abrangente sobre a disciplina, mas que refletisse o curso como um todo, optamos por uma análise que iniciasse em um sistema macro, considerando os projetos político-pedagógicos dos cursos, chegando até o desenvolvimento da disciplina em si. No entanto, é oportuno destacar que, neles, a informação circula em sentido único, uma vez que não se pode exigir de documentos informações suplementares, como é feito nas entrevistas, por exemplo.

Por fim, sempre após a realização de uma sessão de observação, de uma entrevista ou da análise de algum documento, sistematizamos em nossas notas de campo as descrições dos 
acontecimentos, do ambiente virtual, das conversas, relacionando-os com nossas ideias, reflexões, insights. Esse procedimento seguiu a orientação de Bogdan e Biklen (1994), que sugerem o registro de notas de campo após cada observação, entrevista, ou qualquer outra seção de investigação.

A análise se apoia na teoria enraizada e na teoria da atividade. Se, por um lado, a Teoria da Atividade evoca e destaca aspectos como unidade de análise, multivocalidade, historicidade e contradições internas, dando suporte para compreender as transformações que ocorrem a partir das interações que se estabelecem entre os seres humanos e o ambiente durante o desenvolvimento de atividades, a Teoria Enraizada sugere ferramentas analíticas que permitem materializar teorizações fundamentalmente emergentes dos dados.

Seaman (2008) argumenta sobre a contribuição mútua do uso da Teoria Enraizada e da Teoria da Atividade para a pesquisa. Para o autor, uma abordagem combinada tem a potencialidade de ajudar o pesquisador a analisar fatores individuais, sociais e culturais em sua natureza multifacetada, bem como suas mudanças históricas. Isto porque a Teoria da Atividade contribui com a ênfase histórica e cultural, enquanto a Teoria Enraizada sugere procedimentos analíticos detalhados, ambas interessadas em processos de mudança sociais.

Da Teoria Enraizada, buscamos em Strauss e Corbin (2008) elementos para realizar a codificação aberta, ou seja, para fazer emergir dos dados temas em evidência, denominados categorias, em busca de similaridades e diferenças. Realizamos também a codificação axial, que consiste no desenvolvimento das categorias produzidas na codificação aberta em termos de propriedades (características) e dimensões (variação dentro de uma propriedade). Outro procedimento empregado foi a codificação seletiva, em que estabelecemos relações intra e entre categorias e construímos teorização. É oportuno destacar que esses processos de codificações (aberta, axial e seletiva) não são lineares e foram finalizados quando foi possível chegar à saturação teórica. Em outras palavras, considerávamos que uma dada categoria poderia ser considerada saturada quando não identificávamos nenhuma nova propriedade ou dimensão.

Com base na vertente da Teoria da Atividade proposta por Engeström (1987, 2001), analisamos os cursos como uma unidade de análise, ou seja, uma "macro" organização sistêmica que é constituída e influenciada por vários sistemas de atividades "menores".

Para tanto, nos apoiamos no primeiro princípio da Teoria da Atividade para caracterizarmos o modo como esse sistema de atividade "maior" se constituiu inicialmente. $\mathrm{Na}$ sequência, consideramos os princípios da multivocalidade e da historicidade para descrevermos e analisarmos, com base nas vozes dos participantes, o modo como esse sistema 
se desenvolveu ao longo do tempo. Nesse processo descritivo e analítico, identificamos tensões ou contradições internas que correspondem ao quarto princípio da Teoria da Atividade. Elas impulsionaram o desenvolvimento do sistema que resultou em transformações. É oportuno destacar que consideramos prematuro afirmar que as transformações identificadas nesta análise correspondam ao quinto princípio sugerido por Engeström (2001), ou seja, não identificamos os fundamentos necessários nesses dados para afirmar que se tratam de transformações expansivas.

\section{Análise de dados}

De acordo com Engeström (2001), o primeiro princípio da Teoria da Atividade preconiza a compreensão da unidade mínima de análise (sistema de atividade). Para tanto, apresentamos na Figura 2 um diagrama que representa essa unidade, ou seja, um sistema de atividade baseado nos projetos político pedagógicos dos cursos (UFMG, 2011; UFMS, 2012; UFU, 2010; UNEB, 2009).

No vértice superior da representação triangular da Figura 2, encontram-se os artefatos, que têm por função mediar a relação dos sujeitos com o objeto da atividade (ENGESTRÖM; SANNINO, 2010). Nos projetos pedagógicos dos cursos analisados, identificamos que essa posição é inicialmente ocupada por: $\mathrm{EaD}$, internet, Matemática, livros didáticos, ambientes virtuais de aprendizagem, vídeo-aulas, áudios, laboratório de informática.

Em sistemas de atividade, a mediação entre sujeitos e objeto também é desempenhada pela comunidade, que está localizada na parte inferior central do diagrama. São considerados partícipes da comunidade todos que compartilham do mesmo objeto do sistema (ENGESTRÖM, 2001). No caso em análise, verificamos que professores, tutores ${ }^{1}$ presenciais $^{2}$ e a distância, coordenadores da $\mathrm{EaD}$, de tutoria e dos cursos, técnicos em informática e equipe multidisciplinar ${ }^{2}$ compõem a comunidade. A pluralidade dessa comunidade já nos dá indicativos da multivocalidade (segundo princípio da Teoria da Atividade) desse sistema, pois seus componentes têm múltiplos pontos de vistas, tradições, crenças, valores, interesses que

\footnotetext{
${ }^{1}$ Tutores, em geral, são licenciados em Matemática, estudantes de pós-graduação, professores de ensino médio ou do ensino superior.

${ }^{2}$ A equipe multidisciplinar é composta por webdesigner, ilustrador gráfico, webmaster, designer instrucional, produtor de vídeo, editor de vídeo, digitador e técnico de suporte tecnológico.
} 
podem se complementar. No entanto, também podem se chocar gerando contradições internas (ou tensões, de acordo com o quarto princípio da Teoria da Atividade).

Motivo: Aumentar a

Motivo: Promover a educação a distância com vistas à inclusão dos habitantes do interior do Brasil e ao desenvolvimento regional. quantidade de professores de matemática. de matemática.

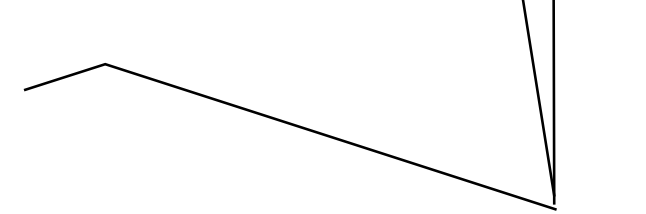

Motivo: Oferecer formação a professores leigos em exercício.

\section{Artefatos:}

EaD, internet, Matemática, livros didáticos, AVA, vídeoaulas, áudios, laboratório de informática.

Formar professores de Matemática no interior do país valendo-se das potencialidades da Educação a Distância (Sistema $\mathrm{UAB})$.

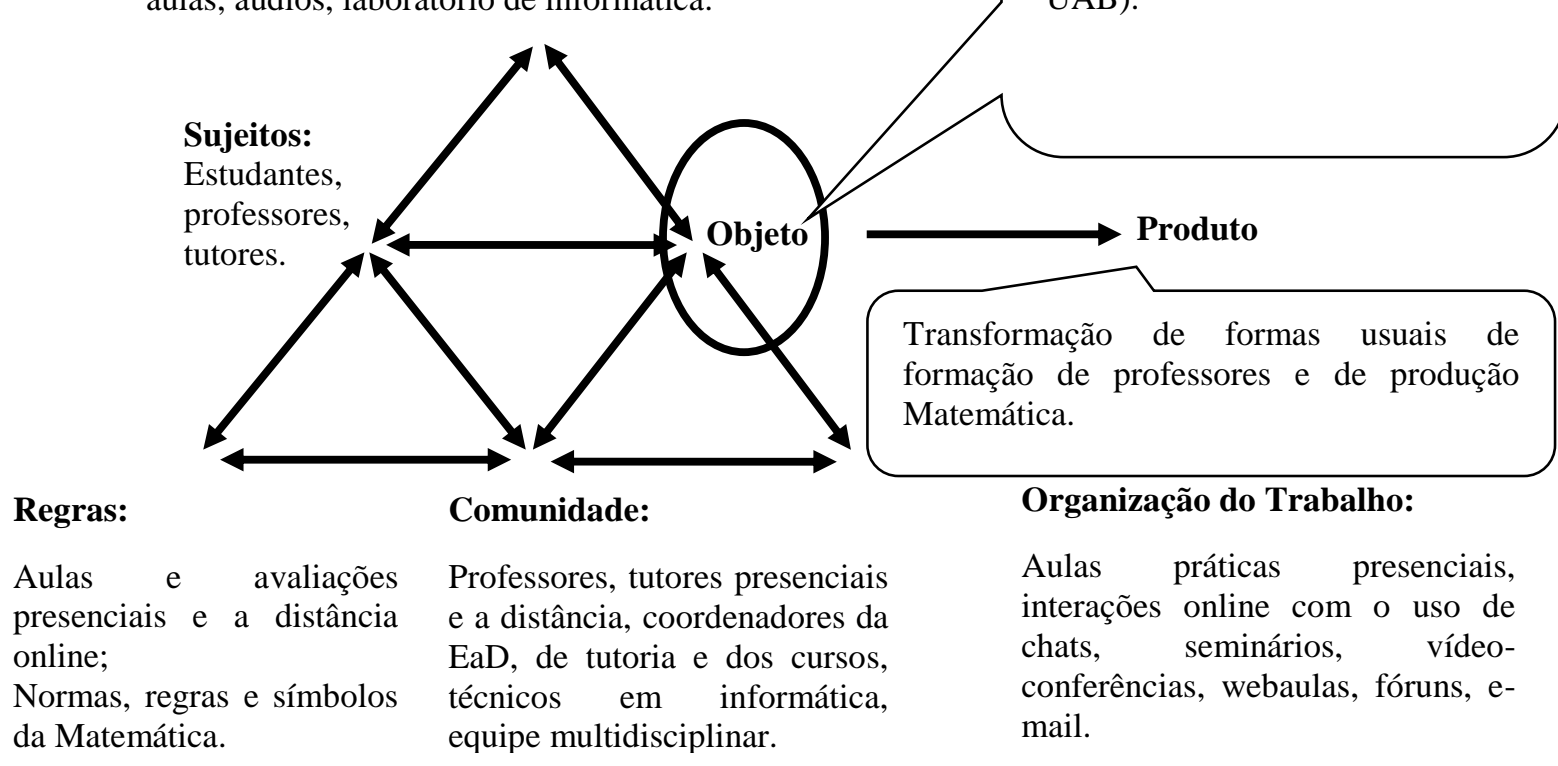

Figura 2 - Representação triangular do sistema de atividade (unidade mínima de análise)

Fonte: Elaboração própria (2018).

De acordo com a Teoria da Atividade, as contradições internas também podem ser consideradas impulsionadoras do desenvolvimento de um sistema. Elas "se colocam", entre outros aspectos, como "desafios ou obstáculos". Quando há uma mobilização em busca da superação destes, em geral é liderada por aqueles que possuem agency (poder de ação), ou seja, os sujeitos. Cremos que são sujeitos do sistema em análise estudantes, professores, tutores.

Ainda no diagrama da Figura 2, é possível observar a tríade sujeitos-regrascomunidade, ou seja, as regras são mediadoras da relação dos sujeitos com a comunidade. Fazem parte das regras todas as formas de regulação das relações dentro do sistema. Desse 
modo, identificamos nesse papel as aulas e avaliações presenciais e a distância online, as normas, regras e símbolos da própria Matemática (Álgebra Linear) que têm sido historicamente construídos.

Por outro lado, é importante verificar que o papel de regulação desempenhado pelas regras influencia diretamente as formas de organização do trabalho. Assim, no sistema em análise, o trabalho foi organizado com aulas práticas presenciais, interações online com o uso de chats, seminários, videoconferências, webaulas, fóruns, e-mail.

Por fim, como resultado da atividade, temos o objeto, que se transforma em produto do sistema. De acordo com Daniels (2011), o objeto pode potencializar o sistema para mudanças, mas, ao mesmo tempo, ele é móvel e se constitui como uma fonte de instabilidade. Com isso, afirma Hardman (2007), a identificação do objeto é algo problemático. Há que se considerar também que as traduções do original russo e/ou diferentes interpretações que estudiosos de outras vertentes da Teoria da Atividade fazem em relação a esse elemento dificultam sua identificação.

No entanto, entendemos que uma caracterização inicial do objeto é necessária. Para tanto, buscamos em Engeström e em outros estudiosos dessa teoria, que se alinham com as ideias desse autor, fundamentos teóricos que nos permitam identificar ou, pelo menos, encontrar uma aproximação do que pode ser considerado objeto inicial do sistema em análise.

Para Engeström (1999), o objeto é entendido como "a matéria-prima" ou "espaçoproblema" para o qual o sistema de atividade é dirigido. Kaptelinin (2005, p. 17) complementa destacando que "o objeto da atividade é determinado cooperativamente por todos os motivos efetivos" e, em adição a isso, Kawasaki (2008) afirma que um motivo pode ser identificado quando os objetivos são discutidos e negociados.

Com bases nesses autores, é possível pensar que os objetivos presentes nos projetos político pedagógicos dos cursos são frutos de discussões e/ou negociações de seus idealizadores, ou seja, eles podem indicar os motivos e, consequentemente, podem levar a uma aproximação do que pode ser considerado o objeto inicial do sistema.

Assim, na parte superior do diagrama da Figura 2 ligados ao objeto destacam-se três motivos identificados nos cursos da UNEB (2009), UFMG (2011), UFU (2010) e UFMS (2012). São eles: promover a educação a distância com vistas à inclusão dos habitantes do interior do Brasil e ao desenvolvimento regional; aumentar a quantidade de professores de Matemática; oferecer formação a professores leigos em exercício. Interpretamos, então, que ao considerarmos esses motivos, uma boa aproximação do objeto é: formar professores de 
Matemática no interior do país, valendo-se das potencialidades da Educação a Distância (Sistema UAB).

Conforme mencionado anteriormente, a transformação do objeto resulta no produto do sistema. Com isso queremos destacar que o produto apresentado no diagrama da Figura 2 resulta de uma inferência realizada com base no conjunto dos elementos que compõem o sistema. Em outras palavras, a transformação de formas usuais de formação de professores e de produção Matemática poderá ocorrer ou não. Isso porque o produto só poderá ser caracterizado em sua totalidade ao final do desenvolvimento do sistema quando as relações dialéticas, que são próprias de sistemas de atividade, ocorrerem.

Apresentar a priori um sistema de atividade, como fizemos no diagrama da Figura 2, exige um esforço complexo, porém fundamental, principalmente em virtude da importância da análise de sua historicidade (terceiro princípio da Teoria da Atividade). Sistemas, sejam eles quais forem, são caracterizados em sua totalidade somente à medida que se desenvolvem.

Cremos que sistemas de atividade devem ser considerados e analisados como algo fundamentalmente dinâmico, fluido e sensível aos movimentos que ocorrem tanto em seu interior como em seu exterior. Observamos que, à medida que os cursos avançavam, em particular, quando a disciplina de Álgebra Linear foi ministrada, esse sistema que os representava se desenvolvia e poderia estar surgindo pelo menos uma contradição interna comum a todos, qual seja: como descrever, comunicar e expressar a linguagem matemática formal no ambiente virtual de aprendizagem?

Observamos indicativos dessa contradição interna durante o processo de codificação axial da Teoria Enraizada. A análise da propriedade conteúdo da categoria "tecnologias digitais como promotoras de variedade comunicacional" resultou em três dimensões, a saber: modo de descrição geométrico; modo de descrição algébrico; e modo de descrição formal. Embora essas dimensões tenham emergido dos dados, optamos por utilizar a mesma terminologia adotada por Hillel (2000). Esse autor explica que cada modo de descrição em Álgebra Linear possui linguagens e notações específicas, assim, determinadas tecnologias podem ser adequadas ou não para representar as linguagens de cada modo.

No caso em análise, consideramos que a falta de adequação dos ambientes virtuais de aprendizagem para representar o modo de descrição (linguagens e notações específicas) das representações geométricas, algébricas e formais da Matemática, ou a não adaptação dos sujeitos ao uso de plug-ins específicos para tal tarefa, gerou a contradição interna no sistema de atividade. $\mathrm{O}$ excerto a seguir é da fala de um dos alunos durante uma das entrevistas. Ele 
reforça os indicativos apresentados anteriormente e, com isso, reafirma nossa análise em relação ao surgimento dessa contradição interna no sistema.

Estudante - [...] Às vezes não tinha como a gente tá inserindo [no AVA] um desenho ou uma fórmula específica dos problemas [...] então, nunca dava certo fazer algo legal [...] assim, a gente ia escrevendo [se refere à linguagem materna] da melhor forma possível para o professor entender o que estávamos questionando (Entrevista realizada em 30/10/2017).

Quando o estudante destaca a dificuldade para inserir no ambiente virtual de aprendizagem "um desenho ou uma fórmula específica", cremos que ele estava se referindo à dificuldade que havia para descrever, comunicar e expressar a linguagem matemática formal. Assim, a contradição interna identificada traduz a tensão produzida por "estar no AVA" e "não ter conhecimento adequado para lidar com as ferramentas que os AVAs fornecem". De acordo com Souto (2013), dificuldades que se tornam obstáculos a serem superados podem contribuir para a caracterização de contradições internas em sistemas de atividade. A esse respeito entendemos que a expressão "nunca dava certo fazer algo legal" sugere o desejo de superação dessa dificuldade. Logo, há uma contradição interna que está relacionada ao modo de descrição das representações geométricas, algébricas e formais da Matemática.

Professora - Lembro-me que no início do trabalho [...] sentia a falta de recursos que nos dessem livre acesso à inserção de símbolos comumente utilizados na Matemática [...] como no trato de matrizes e vetores. [...] eu buscava realizar as explicações utilizando apenas a língua materna. No entanto, como nem sempre isso era possivel, eu sempre procurei resolver um problema ou exemplificar algo [...] por meio de um arquivo em Word, disponibilizado em anexo à mensagem inserida no fórum (Entrevista realizada em 31/10/2017).

O excerto da entrevista da professora indica a mesma dificuldade/insatisfação apresentada pelo estudante. Neste caso, a segunda alternativa, depois da tentativa inicial de uso apenas da linguagem materna, foi utilizar os recursos do editor de texto Word. No entanto, a linguagem matricial, por exemplo, característica do modo algébrico, normalmente é mais trabalhosa para ser "digitada" no computador, mesmo que exista plug-in que dê suporte à simbologia Matemática. A partir desse contexto, uma recomendação da professora parece que contribuiu para a superação da contradição interna.

Professora - quando eu observava que demandaria muita simbologia e outras representações matemáticas [...] pedia que os alunos resolvessem os problemas no papel e lápis e que digitalizassem as respostas para que eu pudesse analisá-las melhor (Entrevista realizada em 31/10/2017).

Essa sugestão da professora foi transformada pelos alunos. A solução final encontrada por eles foi utilizar fotografias para fazer o registro de cálculos no papel para depois compartilhá-los nos fóruns (Figura 3). 


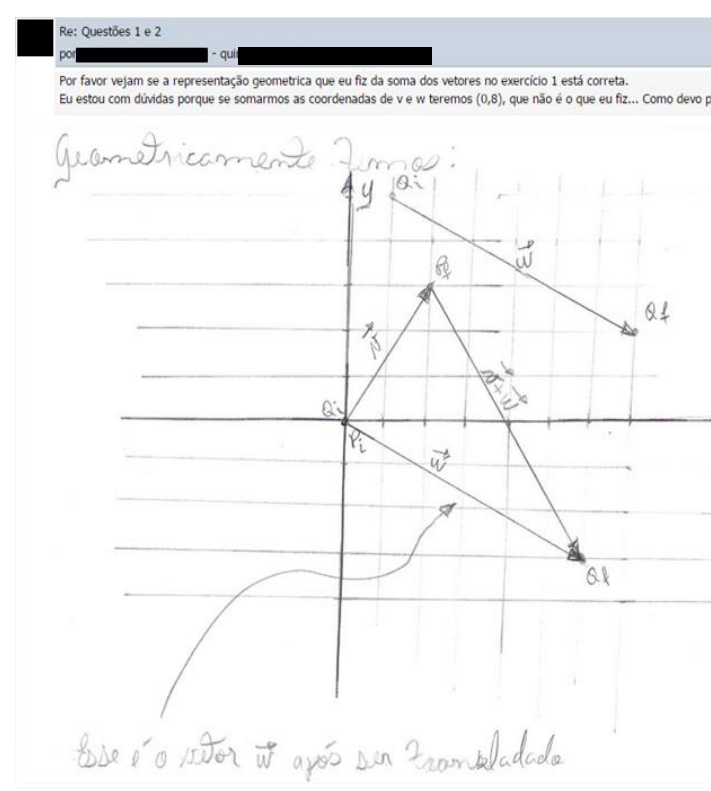

Figura 3 - Modo de descrição geométrico no fórum

Fonte: Moodle da UFMG (2013).

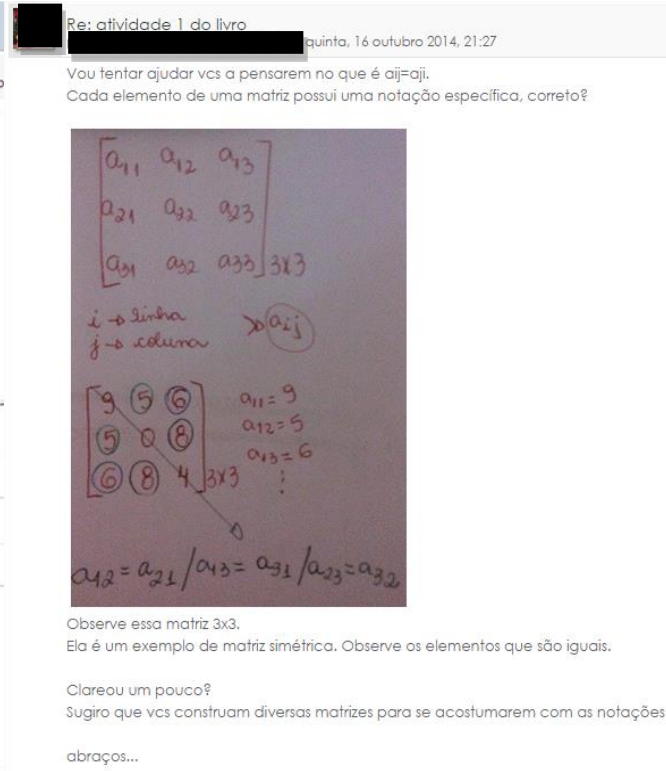

Figura 4 - Modo de descrição algébrico no fórum Fonte: AVA da UFMS (2014).

Entendemos que a contradição interna causada pela falta de adequação do ambiente virtual de aprendizagem para representar o modo de descrição (linguagens e notações específicas) das representações geométricas, algébricas e formais da Matemática mobilizou os sujeitos do sistema fazendo com que eles buscassem uma solução para superá-la. Nesse movimento de busca optaram em inserir um novo artefato ao sistema: a fotografia. Desse modo, interpretamos que a própria restrição do ambiente virtual de aprendizagem pode ser considerada um agency, pois mobilizou o sistema. A nosso ver, estaria ele, então, naquele instante, compondo também o papel de sujeito sem deixar de ser artefato.

Entendemos também que o tratamento de expressões matemáticas como imagem (fotografias) passou a ser algo recorrente, não apenas entre os estudantes, mas também entre os tutores e professores (Figura 4), em diferentes instituições dentre as que analisamos, ainda que elas não mantivessem troca de informações sobre o andamento de suas atividades. Esse procedimento também aponta sinais de mudanças nas regras e na organização do trabalho no sistema de atividade. Isso porque a fotografia não era, até então, algo usual nos cursos, nem mesmo estava prevista. Ela mudou as regras porque rompeu com o que estava planejado em relação às postagens nos fóruns e, com isso, a organização do trabalho também mudou. Responder ou discutir um dado problema, esclarecer ou tirar uma dúvida, que eram processos realizados diretamente no ambiente virtual de aprendizagem por meio da língua materna, passaram a ser feitos com a associação de fotografias tiradas com o celular e que registravam 
os modos de descrição de maneira muito semelhante às representações formais, só que feitos a próprio punho, com lápis e papel.

Iremos aprofundar nossa análise a partir de três situações. A primeira delas refere-se ao modo de descrição geométrico no fórum. O estudante tinha uma dúvida sobre a resolução de um exercício sobre soma de vetores. A fotografia da representação (Figura 3) foi feita pelo estudante e postada no fórum na expectativa de que algum tutor, professor ou colega pudesse contribuir com ele.

Na segunda situação (na Figura 4), o esquema apresentado da fotografia feita pela tutora, ao circular elementos iguais e traçar uma linha reta na diagonal principal, como se dividisse a matriz ao meio, seria mais complicado de ser construído no computador. Isso envolveria um trabalho de inserção de símbolos que tomaria mais tempo. Neste caso, ela fez o esquema da explicação em papel, registrou em fotografia e complementou digitando parte da explicação no próprio fórum.

Nesses dois modos de descrição, algébrico e geométrico, a fotografia foi feita por uma máquina digital ou celular e utilizada distintamente: no modo algébrico, como uma possível forma de acelerar a postagem de matrizes no fórum, e no modo geométrico, como uma forma de compartilhar representações gráficas que, sem o auxílio de uma mesa digitalizadora ou de um software específico, seriam mais complicadas de serem reproduzidas no computador. A partir do momento em que a fotografia se torna digital e pública entre os participantes do curso, qualquer um pode fazer seu download e inserir edições, democratizando acesso e produção.

Neste instante do desenvolvimento do sistema de atividade, é possível verificar novamente mudança nas regras e na organização do trabalho. Ao que parece, fotografar se tornou uma regra, pois ela passou a ser utilizada com frequência nas postagens para expressar conceitos matemáticos ou o seu modo de representação. Por outro lado, o fato de a fotografia se tornar digital, com a possibilidade de ser editada por qualquer um dos participantes do curso, transformou a organização do trabalho, pois tornou-a propícia para produções coletivas e colaborativas.

A terceira situação se refere ao modo de descrição formal no fórum. Em dado momento, a professora estava explicando a resolução de exercícios que envolvem o cálculo do núcleo de uma transformação linear. Mesmo existindo plug-in específico que suporta simbologia matemática no AVA, a postagem da professora combina o uso de captura de imagem da tela do computador a partir de um editor de texto. Em outras palavras, embora não seja uma fotografia propriamente dita, é um caso análogo ao já apresentado anteriormente, 
mas aqui um editor de texto com diversas ferramentas foi utilizado, incluindo o uso de simbologia matemática. A professora redige o texto matemático que deseja compartilhar, faz as edições, tira uma captura da tela, provavelmente a recorta em um editor de imagem e, em seguida, posta a figura no fórum.

Um tempo depois, uma estudante editou uma das imagens postadas pela professora, inserindo uma pergunta em vermelho, que pode ser observada na Figura 5.

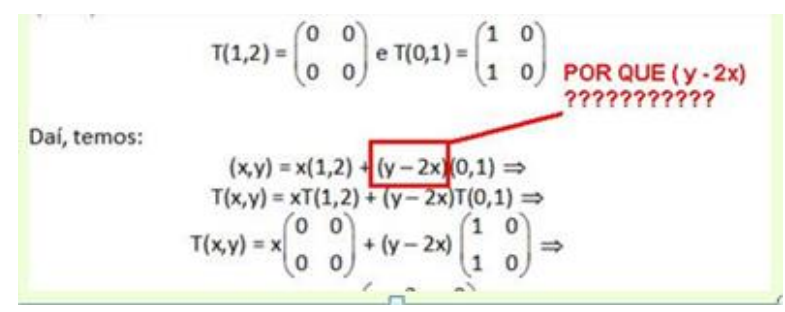

Figura 5 - Parte da postagem de uma estudante em um fórum Fonte: AVA da UNEB (2014).

O destaque em vermelho na Figura 5 mostra que a estudante questionava o porquê de aparecer o termo $(y-2 x)$ no desenvolvimento do raciocínio. Essa dúvida já havia sido apresentada anteriormente por dois estudantes e respondida pela professora. Quatro minutos depois, a mesma aluna postou a seguinte mensagem: "Já vi a explicação da prô. Compreendi, desculpe ter postado sem ter lido antes!" (Inserir fonte. Sugiro usar a mesma da Figura 5), sinalizando que já havia compreendido, pois encontrou a explicação que a professora havia dado anteriormente aos dois colegas.

Essa sequência de interações sinalizou que o registro da comunicação serviu para que outros alunos, além dos dois que questionaram a professora inicialmente, pudessem sanar suas dúvidas e estudar. Assim, reafirmamos que a forma como os alunos utilizaram o ambiente virtual de aprendizagem, possibilitada pelas tecnologias digitais em uso e pela internet, transformou as regras do sistema, ou seja, a maneira como a utilização desse ambiente estava inicialmente prevista: no lugar de apenas os materiais postados servirem como material didático digital, como o livro em extensão PDF e diversas vídeo-aulas, por exemplo, a própria interação por escrito com a professora e estudantes, registrada no ambiente, se tornou material didático.

Desse modo, compreendemos que, na elaboração desse material, tanto estudantes como a professora foram coautores. Portanto, pode-se dizer que ele está impregnado das múltiplas vozes do sistema (ENGESTRÖM, 1987, 2001) e apresenta características de interatividade (SILVA, 2000, 2010). Nesse caso, denominamos este material didático produzido em coautoria, e possibilitado pela presença de internet, de "Material Didático Digital Interativo" (MDDI) (CHIARI, 2015). 
A noção de MDDI integra duas categorias identificadas na codificação aberta e desenvolvidas na codificação axial da Teoria Enraizada em uma categoria central (resultante da codificação seletiva), que poderia ser descrita como: as tecnologias digitais transformando o ambiente virtual de aprendizagem em material didático digital interativo, a partir do registro automático da comunicação.

Do ponto de vista do construto seres-humanos-com-mídias, entendemos que se trata de um tipo de interação bastante particular às mídias presentes. A noção de moldagem recíproca (BORBA; VILLARREAL, 2005) está alinhada à análise que fizemos dessa situação, pois, por um lado, o registro automático moldou a maneira como a estudante sana sua dúvida: a interação não foi diretamente com a professora, mas sim com um registro de uma interação da docente direcionada a outro aluno. Por outro lado, a interação em si molda qual registro é armazenado no AVA, pois esse registro é construído de forma automática enquanto os participantes alimentam o ambiente.

A nosso ver, houve uma transformação do objeto da atividade que, conforme apontado anteriormente, naquele instante era produzir conhecimento sobre elementos algébricos com interações no ambiente virtual de aprendizagem e resultou em MDDI gerado pelo tipo de uso das mídias.

Compreendemos que o MDDI produzido em cada ambiente virtual de aprendizagem é único para cada oferecimento da disciplina e é construído a partir das necessidades que surgem no sistema e não de um planejamento prévio do professor ou do tutor. Isso porque sua constituição é influenciada, principalmente, pela multivocalidade do sistema de atividade. Cada estudante, professor, tutor e até mesmo a internet utilizada em uma dada oferta da disciplina carregam consigo diferentes valores, histórias, convenções, posicionamentos, enfim, são "múltiplas vozes" que, ao interagirem, transmitem esses aspectos tanto para o sistema, quanto ao MDDI. No diagrama da Figura 6 o sistema de atividade está representado em seu formato final. 
Motivo: estudar no ambiente virtual de aprendizagem com interações online
Motivo: compreender os conceitos de Álgebra Linear.
Motivo: cursar a disciplina de Álgebra Linear.

\section{Artefatos:}

$\mathrm{EaD}$, internet, Matemática, disciplina de Álgebra, livros didáticos, AVA, vídeo-aulas, áudios, fotografia.

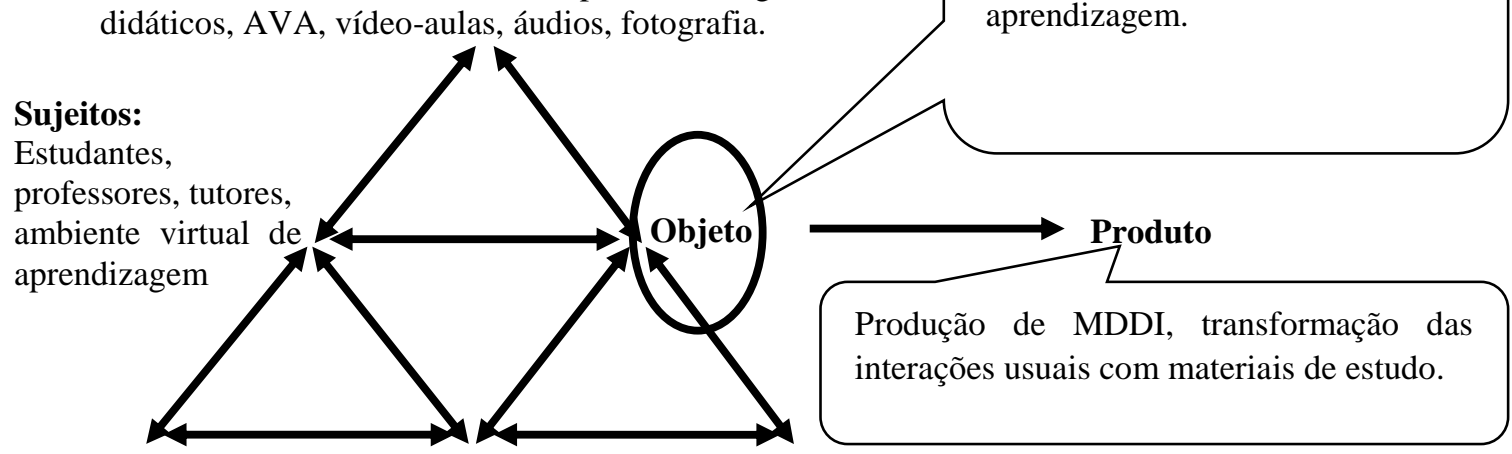

\section{Regras:}

Aulas e avaliações presenciais e a distância online;

Normas, regras e símbolos da Matemática; fotografar.
Comunidade:

Professores, tutores presenciais e a distância, coordenadores da $\mathrm{EaD}$, de tutoria e dos cursos, técnicos em informática, equipe multidisciplinar.
Produzir conhecimento sobre elementos de Álgebra Linear com interações no ambiente virtual de aprendizagem.

Figura 6 - Representação triangular final do sistema de atividade. Fonte: Elaboração própria (2018).

Na Figura 6 está representado o diagrama do sistema de atividade que se constituiu durante o desenvolvimento da disciplina de Álgebra Linear. Na condição de artefatos, inicialmente houve a inserção dos conceitos próprios da Álgebra Linear. No decorrer da disciplina, a restrição do ambiente virtual de aprendizagem para descrição, comunicação e expressão da linguagem matemática formal gerou uma contradição interna. Com isso, houve mobilizações no sistema de atividade que trouxeram a fotografia e áudios para desempenharem o papel de artefatos. Assim, entendemos que o ambiente virtual de aprendizagem teve agency podendo compartilhar com estudantes, professores e tutores o papel de sujeito no sistema. Fotografar passou a ser uma nova regra no sistema, o que favoreceu a organização de um trabalho coletivo e colaborativo.

Engeström (1987) explica que sistemas de atividades são abertos. Logo, a introdução de algo novo como, por exemplo, novos instrumentos, regras, artefatos, etc. podem provocar contradições internas, que, por sua vez, podem impulsionar o sistema para uma mudança. Ao que parece, a contradição interna observada no sistema de atividade surgiu em virtude da inserção da disciplina de Álgebra Linear na condição de artefato e alavancou mudanças no 
sistema. Algumas delas impactaram de forma mais direta nos motivos e, consequentemente, no objeto do sistema.

Os motivos passaram a ser: cursar a disciplina de Álgebra Linear; compreender os conceitos algébricos; estudar no ambiente virtual de aprendizagem com interações online. Com isso, cremos que uma boa aproximação do objeto transformado é: produzir conhecimento sobre conceitos de Álgebra Linear com interações no ambiente virtual de aprendizagem.

Por fim, verifica-se no sistema representado na Figura 6 que motivos e consequentemente o objeto foram transformados resultando em um novo produto. Todo material postado (fotografias, vídeos, áudios) poderia ser editado por qualquer um dos participantes e compartilhado novamente no AVA. Com isso, ocorreu uma transformação das interações usuais com materiais de estudo, resultando no Material Didático Digital Interativo, que é uma produção coletiva, colaborativa e multivocal, construída por e para estudantes e outros atores dos cursos.

\section{Considerações finais}

Se em Borba, Chiari e Almeida (2018) discutimos novos papéis de alunos, professores e da própria tecnologia em AVAs de cursos a distância, neste artigo discutimos o modo como a linguagem matemática formal, as tecnologias digitais, a internet, os ambientes virtuais de aprendizagem e a interação entre participantes podem influenciar e transformar a produção de conhecimento nesses cursos. Nos apoiamos em vertentes teóricas contemporâneas que veem o processo de produção de conhecimento com dimensões emocionais, sociais, históricas, culturais e que incluem novos modos de pensar.

A análise dos dados nos permite afirmar que a restrição dos ambientes virtuais de aprendizagem em relação ao registro da linguagem matemática formal gerou tensões que mobilizaram os participantes dos cursos. Após muitas tentativas, discussões e troca de ideias, a tensão foi "superada" por eles com o uso de fotografias, captura da tela do computador, fóruns, chats e videoconferências.

Nessas mobilizações nos chamou atenção que a solução referente à tensão gerada pela representação da linguagem matemática não veio de forma natural e imediata. Em outras palavras, queríamos compreender o porquê da tensão. Nos questionamos: se o uso da fotografia com dispositivos móveis, como, por exemplo, o celular, que hoje em dia já vem com câmera digital integrada, é algo muito utilizado e é feito diariamente, por que essa 
solução não foi encontrada de imediato pelos participantes dos cursos? Por que demandou tanta troca de ideias? Não há resposta única para essas interrogações. No entanto, cremos que esse tipo de acontecimento não é um caso isolado dentro da Educação Matemática. O que queremos dizer é que estudantes, professores e tutores sabem e utilizam tecnologias digitais em situações rotineiras como compras online, transações bancárias, envio de mensagem e fotos pessoais, etc. No entanto, têm dificuldade para relacionar a possibilidade de utilização dessas mesmas tecnologias no Ensino da Matemática.

Desse modo entendemos que a contradição interna identificada no sistema está intimamente relacionada a outras contradições que estão sendo historicamente construídas e que estão presentes em nossas salas de aula, sejam elas presenciais ou online: como utilizar pedagogicamente as tecnologias digitais no Ensino da Matemática? Qual o papel das tecnologias digitais no processo de produção de conhecimento?

Parece-nos que a não superação da primeira dessas contradições pode resultar na domesticação de mídias, ou seja, não se exploram elementos inerentes do contexto digital e virtual e acabam se reproduzindo práticas constitutivas de outras mídias (BORBA; GADANIDIS, 2008). Em relação à segunda, os dados indicaram que as tecnologias digitais foram protagonistas desempenhando vários papéis de forma simultânea: artefatos, sujeitos, regras, organização do trabalho, objeto e produto.

Em síntese, a dificuldade em comunicar e expressar a linguagem matemática formal no ambiente virtual de aprendizagem gerou tensões e transformações que resultaram na produção poliautoral e multivocal de Material Didático Digital Interativo.

\section{Agradecimentos}

Gostaríamos de agradecer à Coordenação de Aperfeiçoamento de Pessoal de Nível Superior (CAPES - Bolsa de Demanda Social), ao Conselho Nacional de Desenvolvimento Científico e Tecnológico (CNPq - processo 304915/2011-4) e à Fundação de Amparo à Pesquisa do Estado de São Paulo (FAPESP - processo 2012/12176-3) pelo financiamento, em momentos distintos, desta pesquisa.

\section{Referências}

BOGDAN, R.; BIKLEN, S. Investigação Qualitativa em Educação: uma introdução à teoria e aos métodos. Porto: Porto Editora, 1994. 
BORBA, M. C.; CHIARI, A. S. S.; ALMEIDA, H. R. F. L. Interactions in virtual learning environments: new roles for digital technology. Educational Studies in Mathematics, p. 1-18, 13 abr. 2018.

BORBA, M. C.; GADANIDIS, G. Virtual communities and networks of practising mathematics teachers: the role of technology in collaboration. In: KRAINER, K.; WOOD, T. (Org.). International handbook of mathematics teacher education. Rotterdam: Sense Publishers, 2008. v. 3. p. 181-206.

BORBA, M. C.; SCUCUGLIA, R. R. S.; GADANIDIS, G. Fases das Tecnologias Digitais em Educação Matemática: sala de aula e internet em movimento. Belo Horizonte: Autêntica, 2014.

BORBA, M. C.; VILLARREAL, M. E. Humans-With-Media and the Reorganization of Mathematical Thinking: information and communication technologies, modeling, experimentation and visualization. New York: Springer, 2005. v. 39.

CHIARI, A. S. S. O papel das tecnologias digitais em disciplinas de Álgebra Linear a distância: possibilidades, limites e desafios. 2015. 200 f. Tese (Doutorado em Educação Matemática) Universidade Estadual Paulista "Júlio de Mesquita Filho", Rio Claro, 2015.

DANIELS, H. Vygotsky e a Pesquisa. São Paulo: Loyola, 2011.

ENGESTRÖM, Y. Activity Theory and Individual and Social Transformation. In: ENGESTRÖM, Y.; MIETTINEN, R.; PUNAMÄKI, R.-L. (Ed.). Perspectives on Activity Theory. UK-USA-Australia: Cambridge University Press, 1999. p. 19-38.

ENGESTRÖM, Y. Expansive Learning at Work: Toward an activity theoretical reconceptualization. Journal of Education and Work, London, v. 14, n. 1, p. 133-156, fev. 2001.

ENGESTRÖM, Y. Learning by expanding: an activity-theoretical approach to developmental reasearch. Helsinki: Orienta-Konsultit, 1987.

ENGESTRÖM, Y.; SANNINO, A. Studies of expansive learning: Foundations, findings and future challenges. Educational Research Review, [S.1.], v. 5, n. 1, p. 1-24, jan. 2010.

FAN, L. Textbook research as scientific research: towards a common ground on issues and methods of research on mathematics textbooks. ZDM, Berlim, v. 45, n. 5, p. 765-777, set. 2013.

HARDMAN, J. Making Sense of the Meaning Maker: tracking the object of activity in a computerbased mathematic lesson using activity theory. International Journal of Education and

Development using Information and Communication Technologies, West Indies, v. 3, n. 4, p. 111130, dez. 2007.

HILLEL, J. Modes of description and the problem of representation in Linear Algebra. In: DORIER, J. L. (Org.). On the teaching of linear algebra. Dordrecht: Kluwer Academic Publishers, 2000. p. 191208.

JACCOUD, M.; MAYER, R. A observação direta e a pesquisa qualitativa. In: POUPART, J. et al. (Org.). A pesquisa Qualitativa: enfoques epistemológicos e metodológicos. 3. ed. Petrópolis: Vozes, 2008. p. 254-294.

KAPTELININ, V.; KUUTTI, K.; BANNON, L. Activity Theory: Basic concepts and application. In: BLUMENTHAL, B.; GORNOSTAEV, J.; UNGER, C. (Org.). Human-Computer Interaction. Lecture Notes in Computer Science. 1995. ed. [S.1.]: Springer, 2005. v. 1015. 
KAWASAKI, T. F. Tecnologias na sala de aula de matemática: resistências e mudanças na formação continuada de professores. 2008. 212 f. Tese (Doutorado em Conhecimento e Inclusão Social - Universidade Federal de Minas Gerais, Belo Horizonte, 2008.

LEONTIEV, A. N. O desenvolvimento do psiquismo. Lisboa: Livros Horizonte, 1978.

LÉVY, P. As tecnologias da inteligência: o futuro do pensamento na era da informática. Rio de Janeiro: Editora 34, 1993.

POUPART, J. et al. A pesquisa qualitativa: enfoques epistemológicos e metodológicos. Petrópolis: Vozes, 2008.

RIBEIRO, M.; AMARAL, R. B. Guia e Tecnologia dos/nos Livros Didáticos de Matemática: uma Primeira Discussão. Educação Matemática em Revista, Brasília, v. 1, p. 64-75, jul. 2016.

SEAMAN, J. Adopting a Grounded Theory Approach to Cultural-Historical Research: Conflicting Methodologies or Complementary Methods? International Journal of Qualitative Methods, [S.1.], v. 1, n. 7, p. 1-17, 2008.

SILVA, M. Sala de aula interativa. YouTube: [s.n.]. Disponível em: https://www.youtube.com/watch?v=EGfw73ZJ14U. Acesso em: 14 jan. 2015., 2010.

SILVA, M. Sala de aula interativa. Rio de Janeiro: Quartet, 2000.

SOUTO, D. L. P.; BORBA, M. C. Seres Humanos-com-Internet ou Internet-com-Seres Humanos: uma troca de papéis? Revista Latinoamericana de Investigación en Matemática Educativa, Cidade do México, v. 19, n. 2, p. 217-242, jul. 2016.

SOUTO, D. P. L. Transformações expansivas em um curso de Educação Matemática a distância online. 2013. 279 f. Tese (Doutorado em Educação Matemática) - Universidade Estadual Paulista "Júlio de Mesquita Filho", Rio Claro, 2013.

STRAUSS, A.; CORBIN, J. Pesquisa qualitativa: técnicas e procedimentos para o desenvolvimento de teoria fundamentada. 2. ed. Porto Alegre: Artmed, 2008.

TIKHOMIROV, O. K. The psychological consequences of computerization. In: WERTSCH, J. V. The concept of activity in soviet psychology. New York: M. E. Sharpe. Inc, 1981. p. 256-278.

UFMG. Projeto Político Pedagógico: licenciatura em Matemática a distância. Belo Horizonte: UFMG, 2011.

UFMS. Projeto Político Pedagógico: licenciatura em Matemática a distância. Campo Grande: UFMS, 2012.

UFU. Projeto Político Pedagógico: licenciatura em Matemática a distância. Uberlância: UFU, 2010.

UNEB. Projeto Político Pedagógico: licenciatura em Matemática a distância. Salvador: UNEB, 2009.

VILLARREAL, M. E.; BORBA, M. C. Collectives of humans-with-media in mathematics education: notebooks, blackboards, calculators, computers and...notebooks throughout 100 years of ICMI. ZDM Mathematics Education, Berlim, v. 42, p. 49-62, 2010.

Submetido em 24 de Setembro de 2018. Aprovado em 27 de Abril de 2019. 